\title{
Eva MARZI, Credo. Une cartographie de la diversité religieuse vaudoise
}

Avec la collaboration de Brigitte Knobel, Irène Becci, Aude Zurbuchen et Chloé Berthet. Lausanne, Antipodes, coll. « Existences et sociétés », 2020, $253 \mathrm{p}$.

Jean-Pierre Bastian

\section{OpenEdition}

Journals

Édition électronique

URL : https://journals.openedition.org/assr/65109

DOI : 10.4000/assr.65109

ISSN : $1777-5825$

Éditeur

Éditions de l'EHESS

Édition imprimée

Date de publication : 4 décembre 2021

Pagination : 350-351

ISBN : 9782713228735

ISSN : 0335-5985

Référence électronique

Jean-Pierre Bastian, «Eva maRzı, Credo. Une cartographie de la diversité religieuse vaudoise », Archives de sciences sociales des religions [En ligne], 196 | octobre-décembre 2021, mis en ligne le 01 décembre 2021, consulté le 13 février 2022. URL : http://journals.openedition.org/assr/65109 ; DOI : https:// doi.org/10.4000/assr.65109

Ce document a été généré automatiquement le 13 février 2022.

(c) Archives de sciences sociales des religions 


\section{Eva MARZI, Credo. Une cartographie de la diversité religieuse vaudoise}

Avec la collaboration de Brigitte Knobel, Irène Becci, Aude Zurbuchen et Chloé Berthet. Lausanne, Antipodes, coll. « Existences et sociétés », 2020, $253 \mathrm{p}$.

Jean-Pierre Bastian

\section{RÉFÉRENCE}

Eva MARZI, Credo. Une cartographie de la diversité religieuse vaudoise. Avec la collaboration de Brigitte Knobel, Irène Becci, Aude Zurbuchen et Chloé Berthet. Lausanne, Antipodes, coll. « Existences et sociétés », 2020, 253 p.

1 Comme partout en Europe, la société suisse se pluralise au plan religieux. Cependant, la régulation des cultes reste une prérogative cantonale et les 26 cantons oscillent entre une laïcité de stricte séparation et un régime de reconnaissance de droit public. Les recherches se mènent souvent au plan cantonal ; c'est le cas de celle mise en œuvre par le Centre intercantonal d'information sur les croyances (CIC) et l'Université de Lausanne en 2017. Elle répond même à une commande du canton de Vaud, soucieux de répertorier les organisations religieuses répandues sur son territoire. Car l'État de Vaud accorde reconnaissance non pas à des religions, mais à des communautés organisées juridiquement. Jusqu'à présent, deux d'entre elles, largement répandues, sont des corporations de droit public dotées de personnalité morale, l'Église évangélique réformée et l'Église catholique romaine, alors que la minorité israélite jouit d'un statut d'intérêt public. Pour les autres minorités religieuses, elles peuvent obtenir ce statut d'intérêt public, véritable outil d'intégration et de régulation, conduisant à des regroupements en cours, comme par exemple des cinq paroisses anglicanes et de la paroisse catholique-chrétienne, ou encore de la Fédération évangélique vaudoise regroupant 42 communautés et de l'Union des associations musulmanes composée de 17 communautés. 
2 La nécessité de connaître le terrain associatif religieux a poussé l'État à mandater le CIC afin de dresser l'inventaire de l'ensemble des communautés "religieuses et spirituelles » et de cartographier leur localisation. Il en ressort une grande diversité composée de 785 communautés, 11 courants religieux et 40 sous-courants. C'est là que réside l'originalité de cette recherche en ne partant pas des options individuelles, mais des pratiques religieuses communautaires dans des lieux de culte. Elle le fait non sans avoir au préalable défini l'objet « comme un groupe de personnes partageant les mêmes croyances et se réunissant régulièrement dans un même lieu de culte " et la religion comme " un ensemble de croyances, rites, pratiques et règles morales » permettant d'entrer en relation avec des réalités suprahumaines répondant à des questions existentielles. Dès lors, le terme englobe un large inventaire allant de la paroisse à la tarîqa soufie en passant par les cercles néo-chamaniques.

3 L'enquête révèle surtout une pluralité interne au christianisme. Cependant, ce courant reste massivement dominant avec 712 des 785 communautés recensées. Pour le reste, l'inventaire des autres communautés selon les intitulés retenus des courants est bref : 3 baha'i, 12 bouddhistes, 15 ésotériques, 6 hindouistes, 24 musulmanes, 1 juive, 3 néochamaniques, 5 Nouveaux mouvements religieux, 1 spiritualiste et 1 taoïste. Chaque courant et sous-courant est minutieusement décrit et expliqué, et même photographié, et surtout cartographié. Il en ressort une riche information historique et sociale concernant chaque courant, mais surtout l'image d'une massive présence chrétienne et d'une anecdotique visibilité des autres courants religieux. Certes, le paysage vaudois continue d'être agrémenté par les édifices religieux correspondant aux communautés villageoises historiques. L'enquête contribue à mettre en exergue cette dimension de " puits de mémoire " (Danièle Hervieu-Léger) du christianisme. Mais, dans le contexte de sécularisation avancée qui caractérise la Suisse, on peut se demander si une telle recherche, bien que fort utile d'un point de vue étatique, ne déforme pas la réalité religieuse qui, si elle n'est pas celle de la « sortie de la religion " (Marcel Gauchet), ne peut pas faire l'économie de la chute des pratiques. En effet, selon le service statistique du canton de Vaud, la part des 817000 Vaudois ne se rattachant pas ou ne faisant pas partie d'une tradition religieuse a plus que doublé entre 2000 et 2017 (passant de $13 \%$ à $33 \%$ ) ; selon les mêmes sources officielles, en 2018, $48 \%$ des Vaudois se déclaraient "sans confession ou autre " que protestant ou catholique. Dès lors, comment concilier l'intitulé du chapitre « un canton de tradition chrétienne avec une forte présence protestante» (p. 52) avec le fait que les statistiques cantonales de 2019 ont encore montré que le nombre de catholiques et de protestants continuait de baisser, respectivement à $27,5 \%(28,8 \%$ en 2018$)$ et $24,4 \%(25,3 \%$ en 2018$)$ ? L'impression cartographique de saturation de lieux de cultes chrétiens ne traduit pas le fait que ces églises sont vides ou ne sont fréquentées que par une minorité religieuse active. De tels relevés à partir des communautés religieuses et leur lieu de culte traduisent certes l'héritage historique d'une imprégnation cultuelle chrétienne, mais ils devraient être fortement pondérés par une analyse qualitative et théorique de l'évolution religieuse. 